\title{
In Vitro Pancreatic Lipase Inhibition by Marine Fungi Purpureocillium lilacinum Associated with Stylissa sp. Sponge as Anti-obesity Agent
}

\author{
Wendi Nurul Fadillah', Nampiah Sukarno ${ }^{2 *}$, Dyah Iswantini ${ }^{3,4}$, Min Rahminiwati ${ }^{5}$, Novriyandi Hanif ${ }^{3}$, Mashuri Waite ${ }^{6}$ \\ 'Study Program of Microbiology, Department of Biology, Faculty of Mathematics and Natural Sciences, IPB University, Bogor, \\ Indonesia \\ ${ }^{2}$ Department of Biology, Faculty of Mathematics and Natural Sciences, IPB University, Bogor, Indonesia \\ ${ }^{3}$ Department of Chemistry, Faculty of Mathematics and Natural Sciences, IPB University, Bogor, Indonesia \\ ${ }^{4}$ Tropical Biopharmaca Research Center, IPB University, Bogor, Indonesia \\ ${ }^{5}$ Department of Anatomy, Physiology, and Pharmacology, Faculty of Veterinary Medicine, IPB University, Bogor, Indonesia \\ ${ }^{6}$ Gill Ewa Lands, Honolulu, Hawaii, USA
}

\section{ARTICLE INFO}

Article history:

Received July 18, 2021

Received in revised form October 4, 2021

Accepted October 18, 2021

\section{KEYWORDS:}

competitive inhibitor,

$\mathrm{IC}_{50}$,

inhibition kinetics,

LC-MS/MS QTOF,

marine fungal extract

\begin{abstract}
This study aimed to evaluate the potential of marine fungus Purpureocillium lilacinum isolated from an Indonesian marine sponge Stylissa $\mathrm{sp}$. as an antiobesity agent through pancreatic lipase inhibition assay. The fungus was identified as $P$. lilacinum through morphological and molecular characteristics. The fungal extract's inhibition activity and kinetics were evaluated using spectrophotometry and Lineweaver-Burk plots. Ethyl acetate and butanol were used for extraction. Both extracts showed pancreatic lipase inhibition in a concentration-dependent manner. Both crude extracts were then fractionated once. All fractionated extracts showed inhibitory activity above $50 \%$, with the highest activity found in fraction 5 of ethyl acetate at $93.41 \%$ inhibition. The best fractionated extract had an $\mathrm{IC}_{50}$ value of $220.60 \mu \mathrm{g} . \mathrm{mL}^{-1}$. The most active fraction of $P$. lilacinum had a competitivetype inhibitor behavior as shown by the value of $\mathrm{V}_{\max }$ not significantly changing from 388.80 to $382.62 \mathrm{mM}$ pNP.min ${ }^{-1}$, and the Michaelis-Menten constant $\left(\mathrm{K}_{\mathrm{M}}\right)$ increased from 2.02 to $5.47 \mathrm{mM}$ in the presence of $500 \mu \mathrm{g} . \mathrm{mL}^{-1}$ fractionated extract. Metabolite identification with LC-MS/MS QTOF suggested that galangin, kaempferol, and quercetin were responsible for the observed lipase inhibition.
\end{abstract}

\section{Introduction}

Sponges (Porifera) are vital organisms maintaining the ecosystem in the coral triangle, a world marine biodiversity hotspot that includes Indonesia. Sponges are sessile organisms that play an important role in maintaining coral reef ecosystems and as hosts for microbial symbionts such as fungi (Taylor et al. 2007). The fungal symbionts in sponges produced diverse secondary metabolites that are beneficial for their hosts. Sponges utilize fungal secondary metabolites for defending against predation and surviving in toxic or extreme environmental conditions (Debbab et al. 2010; Wahl et al. 2012). The association between sponges and marine fungi may also produce unique and novel natural products potentially beneficial as new drugs to overcome medical problems such as multidrug-resistant pathogenic microbes, infectious diseases, and metabolic diseases (Doshi et al. 2011;

\footnotetext{
* Corresponding Author

E-mail Address: nampiah@apps.ipb.ac.id
}

Pimentel et al. 2011). In 2017, 1490 new natural products were reported from marine organisms and marine fungi contributed 30\% of these new natural products (Carroll et al. 2019). However, in spite of being one of the great epicenters of marine biodiversity, Indonesia has few reports of marine fungal secondary metabolites (Hanif et al. 2019).

Obesity is a common disease occurring in many developing countries, including Indonesia. Studies in Indonesia reported that as much as $16.5 \%$ of children and $45.7 \%$ of adults are obese (Sari and Amaliah 2014; Rachmi et al. 2016), with obesity prevalence higher among male children and female adults (Rachmi et al. 2017). In general, obesity is treated by limiting dietary intake of fat, controlling the absorption of dietary fat, and/or controlling the storage and metabolism of fat and glucose in the body. Several drugs have been developed for anti-obesity, such as sibutramine, lorcaserin, rimonabant, and orlistat. However, adverse effects have been reported for each of these drugs. 
Sibutramine, a centrally acting phenethylamine class of drug used for long-term treatment of obesity in adults, reduces food intake by selective inhibition of the re-uptake of noradrenaline, serotonin, and dopamine, resulting in thermogenesis and lipolysis. Common side effects of sibutramine are due to activation of the sympathetic nervous system and include dry mouth, insomnia, constipation, headache, anorexia, hypertension, and increased pulse rate (Elangbam 2009). Lorcaserin, a selective 5-HT2C receptor agonist located in various parts of the brain and hypothalamus, has serotonergic properties which act as an anorectic resulting in weight loss through hypophagia (Lam et al. 2008). Rimonabant, an appetite suppressant, blocks the cannabinoid-1 (CB1) receptors, and thus decrease demand for food. Rimonabant side effects include mood changes, nausea and vomiting, diarrhea, headache, dizziness, and anxiety (Kaila and Raman 2008).

In contrast, as the most accepted drug by the FDA for obesity treatment, orlistat is a hydrogenated derivative of lipstatin produced by Streptomyces toxytricini and acts by diminishing the absorption of dietary fat by inhibiting pancreatic lipase activity. Orlistat is an irreversible inhibitor targeting the active site of pancreatic and gastric lipase, binds covalently to the serine residue on the active site preventing the intraluminal hydrolysis of triglyceride and resulting in an increase in fecal fat excretion (Heck et al. 2000). Drugs with covalent inhibitory mechanism of action provides many pharmacological advantages over drugs with reversible mechanism of action; these advantages include enhanced potency, selectivity, and prolonged activity (Singh et al. 2011).

Despite the great potential of covalent inhibition, there are several potential downsides and limitations of this drug class. The longer residence time of these drugs can lead to toxicity which can generate adverse clinical outcomes if these drugs are used long-term (De Cesco et al. 2017). Orlistat is reported to deliver adverse effects, including liquid stools, steatorrhea, fat-soluble vitamin deficiencies, fecal urgency, and flatus incontinence (Kaila and Raman 2008). If consumed long-term, orlistat may cause hepatotoxicity, gallstone formation, kidney stones, and acute pancreatitis (Katoch et al. 2017). There has been a great interest among researchers in finding pharmacologically active molecules with fewer side effects.

The marine sponge Xestospongia testudinaria from China has been found to produce the pancreatic inhibitor xestonariena I from an unknown biosynthetic pathway (Yang et al. 2017). Several marine fungi from the Aspergillus group associated with a marine sponge from the South China Sea were also reported to be a source of pancreatic lipase inhibitors, such as flavipesides A-C from Aspergillus flavipes 164013 isolated from a marine sponge Dysidea sp. and petrosamides A-C from Aspergillus sp. 151304 associated with marine sponge Petrosia sp. (Jiao et al. 2020; Tang et al. 2020). The biodiversity of marine fungi and their potential in Indonesia are high. However, research on sponge-associated marine fungi in Indonesia and their potential as a source of anti-obesity metabolites has not been carried out. We began our research to fill this gap. The main objective of this research was to investigate marine spongeassociated fungi as secondary metabolite producers to inhibit pancreatic lipase activity to potentially treat obesity.

\section{Materials and Methods}

\subsection{Marine Fungal Isolation}

Purpureocillium lilacinum IPBCC.19.1498 was isolated from a marine sponge Stylissa sp. collected from Pramuka Island, Seribu Archipelago, Jakarta, Indonesia. Fungal isolation was carried out as follows: the sponges were cut and collected into a sterile container at depths of $\pm 10 \mathrm{~m}$ underwater to prevent contact of tissue with air. Then, the samples were stored at $4^{\circ} \mathrm{C}$ prior to fungal isolation at the laboratory. The sample was surface sterilized with sterile water prior to fungal isolation by a direct isolation method following Zhang et al. (2009) with slight modification. Samples were cut into large pieces and separated based on cuts such as an outer layer, middle layer, and inner layer of sponges. Then, the big pieces were rinsed three times with sterile water and cut further into small pieces of $1 \mathrm{~cm}^{3}$. The pieces were then planted into potato dextrose agar (PDA) with $75 \%$ seawater. The medium also contained chloramphenicol antibiotic (500 mg.L $\mathrm{L}^{-1}$ ) and rose bengal fungistatic ( $30 \mathrm{mg} . \mathrm{L}^{-1}$ ) and then incubated at $27^{\circ} \mathrm{C}$ for a month. The fungal isolation was done by planting three pieces of sample in each petri dish and was done in three replicates. The fungi that emerge from the samples' pieces were transferred onto new medium to obtain pure cultures.

\subsection{Morphological and Molecular Analysis of Fungi}

The morphological identification followed the method reported by Luangsa-Ard et al. (2011). In brief, the fungus was grown on PDA at $27^{\circ} \mathrm{C}$ and incubated for seven days. The morphological and micromorphological features such as colony 
characteristics, conidiophores, phialides, and conidia were measured.

The fungal genome DNA was isolated following the method of Sambrook et al. (1989). Briefly, the fungal isolates were cultured on cellophane membrane on PDA at $27^{\circ} \mathrm{C}$ for five days prior to cell harvesting for genome DNA extraction. The mycelium was harvested and ground with a sterile pestle. Fungal genome DNA was extracted using the cetyl trimethyl ammonium bromide (CTAB) buffer lysis solution followed by washing with phenol-chloroform-isoamyl alcohol (PCI) mixture and precipitated with ethanol. The DNA quality was measured with nanodrop.

The fungal genome DNA was used in PCR as a template to amplify the fungal ITS rDNA region using primers ITS1 and ITS 4 (White et al. 1990). The reaction mixture contained $12.5 \mu \mathrm{l}$ PCR master mix (kappa fast 2G), $1.5 \mu$ l of 10 pmol primer (each), 3 $\mu l$ of $100 \mathrm{ng}$ DNA template and $6.5 \mu \mathrm{l}$ NFW. PCR conditions were as follows: initial denaturation $\left(94^{\circ} \mathrm{C}\right.$ for $5 \mathrm{~min}) ; 30$ cycles of denaturation $\left(94^{\circ} \mathrm{C}\right.$ for $\left.30 \mathrm{~s}\right)$, primer annealing $\left(55^{\circ} \mathrm{C}\right.$ for $1 \mathrm{~min}$ ), and elongation $\left(72^{\circ} \mathrm{C}\right.$ for $2 \mathrm{~min}$ ), with a final elongation at $72^{\circ} \mathrm{C}$ for 10 min. PCR products were purified prior to sequencing analysis. The sequencing result was then analyzed for its homologous sequences within the GenBank and MycoBank databases by using the program Basic Local Alignment Search Tool (BLAST) at http://blast.ncbi. nlm.nih.gov. Phylogenetic trees were constructed by using MEGA 6.0 program.

\subsection{Fungal Extract Production}

Fungal extract and fractionated extract were conducted following protocols by Ebadda et al. (2008) and Kjer et al. (2010). The fungus was cultivated in PDA with $75 \%$ seawater without antibiotic. Plugs of agar supporting mycelium growth were transferred to 31 of potato dextrose broth (PDB) medium. Flasks were incubated at $27^{\circ} \mathrm{C}$ in constant shaking at $150 \mathrm{rpm}$ for seven days. The broth culture was then harvested by separating from mycelia.

The crude extract was obtained by extracting broth culture gradually using ethyl acetate followed by n-butanol as organic solvent and evaporated under vacuum. The extracts were chromatographed on Silica and XAD resins with gradient eluent to give extract fractions. The dried crude extract and the fractionated extract were reconstituted in DMSO for further analysis.

\subsection{Assay of Inhibitory Effect on the Pancreatic Lipase Activity}

Lipase activity was determined by measuring p-nitrophenol (pNP) concentration released from the activity between lipase and p-nitrophenyl butyrate (pNPB). The activity was measured by spectrophotometry following procedures from Chedda et al. (2016) with slight modification for absorbance measurements optimizations. Total assay volume was $200 \mu \mathrm{l}$ containing $25 \mu \mathrm{l}$ of $500 \mu \mathrm{l} . \mathrm{mL}^{-1}$ pNPB, $50 \mu \mathrm{l}$ of $200 \mu \mathrm{g} . \mathrm{mL}^{-1}$ porcine pancreatic lipases, and $25 \mu \mathrm{l}$ sample in dimethyl sulfoxide (DMSO). The reaction was brought to $200 \mu$ l with $100 \mathrm{mM} \mathrm{pH} 7.2$ phosphate buffer saline (PBS). The test solution was incubated for 30 minutes at $37^{\circ} \mathrm{C}$ prior to measuring pNP at $400 \mathrm{~nm}$ using an ELISA plate reader (Biotek). The sample was assayed in three replicates, and the results were reported as a mean of replicates measurements.

The percentage of inhibitory activity was calculated using the following formula:

$$
\% \text { Inhibition }=\frac{\begin{array}{c}
\text { Absorbance of } \\
\text { blank }
\end{array}-\begin{array}{c}
\text { Absorbance of } \\
\text { sample }
\end{array}}{\text { Absorbance of blank }} \times 100
$$

The absorbance of blank and absorbance of the sample were corrected by measuring the activity without using enzyme in the assay mixture. Orlistat was used as the positive control. The test was done in every step of bioactivity monitoring of fungal extract. The fractionated extract with the greatest inhibitory activity was then selected and subjected to $\mathrm{IC}_{50}$ and inhibition kinetics assay. This selected most active fractionated extract was diluted with DMSO in various concentrations to prepare the required inhibitor concentration used in the $\mathrm{IC}_{50}$ assay.

\subsection{Inhibition Kinetics of Selected Fractionated Extract}

The substrate stock solution of pNPB was prepared freshly in acetonitrile $\left(1 \mu \mathrm{l} . \mathrm{mL}^{-1}\right)$. The stock was then diluted with phosphate buffer to prepare the required concentrations between 2.3 to $6.0 \mathrm{mM}$. The inhibition kinetics of the most active fractionated extract were carried out by measuring assay mixtures with various substrate concentrations and incubated at $37^{\circ} \mathrm{C}$ for 1 hour. The mixtures were measured for every 5 minutes of incubation to obtain the enzyme activity rate across multiple substrate concentrations.

\subsection{Metabolites Identification by LC-MS/MS QTOF Screening}

The most active fractionated extract was then subjected to LC-MS/MS QTOF to screen the metabolites present in the extract. The screening criteria was selected from flavonoid, alkaloid, tannin, steroid, saponin, and triterpenoid groups. The screening was required to meet four criteria to 
ensure the metabolites were present in the extract. The criteria were as follows:

- Mass error $\leq 5 \mathrm{ppm}$

- Isotope match MZ RMS PPM $\leq 6 \mathrm{ppm}$ and isotope match MZ RMS \% $\leq 10 \%$

- Intensity/Response $\geq 300$

- Fragment match $\geq 1$ mass fragment

\section{Results}

\subsection{Fungal Isolation and Identification 3.1.1. Fungal Isolation and Morphological Characteristics}

The fungus was successfully isolated from the middle layer of the Stylissa sp. sponge. The fungus was found grown in two pieces of the sponges. The fungus was identified as Purpureocillium lilacinum IPBCC.19.1498 based on morphological characteristics (Figure 1). The fungal characteristics were as follows. Colonies at $27^{\circ} \mathrm{C}$ on PDA (Oxoid) attained 17.00$18.47 \mathrm{~mm}$ diameters after seven days of incubation. Colonies consisted of basal felt of numerous conidiophores with a floccose overgrowth of aerial mycelium, purple in color; reverse colony mostly in shades of purple. Somatic hyphae were hyaline, smooth-walled, 1-3 $\mu \mathrm{m}$ wide. Conidiophores were up to $100 \mu \mathrm{m}$ long; stalks with roughened thick walls 3-6 $\mu \mathrm{m}$ wide consisting of verticillate branches with whorls of 2-4 phialides. Conidiophores sometimes grew irregularly branched, septate, hyaline and smooth-walled. Phialides were 7-15 × 2-3 $\mu \mathrm{m}$, having a swollen basal portion tapering into a short distinct neck about $1 \mu \mathrm{m}$ wide. Conidia were in long dry chains, ellipsoidal to fusiform, $2-3 \times 2-4 \mu \mathrm{m}$, smooth-walled, mostly subhyaline, chlamydospores absent.

\subsubsection{Molecular Analysis of Fungi}

Further identification using molecular features showed that the identification result with BLAST analysis is in agreement with that of the morphological analysis. The fungus has $100 \%$ similarity with $P$. lilacinum(AB_103380). The results of the phylogenetic analysis supported that of the BLAST analysis. The phylogenetic tree of the fungus was constructed with the maximum likelihood method based on the Tamura 3-parameter model by using MEGA 6.0 program, and a total of 17 OTU were used in the analysis of ITS rDNA sequences with Paracremonium binnewijzendii CBS 143277 as an outgroup (Table 1 ). The dataset consists of 665 nucleotide characters for the analyses, 479 were constant and 186 were variable.

The Maximum likelihood analysis inferred by Tamura 3-parameter model yielded the highest

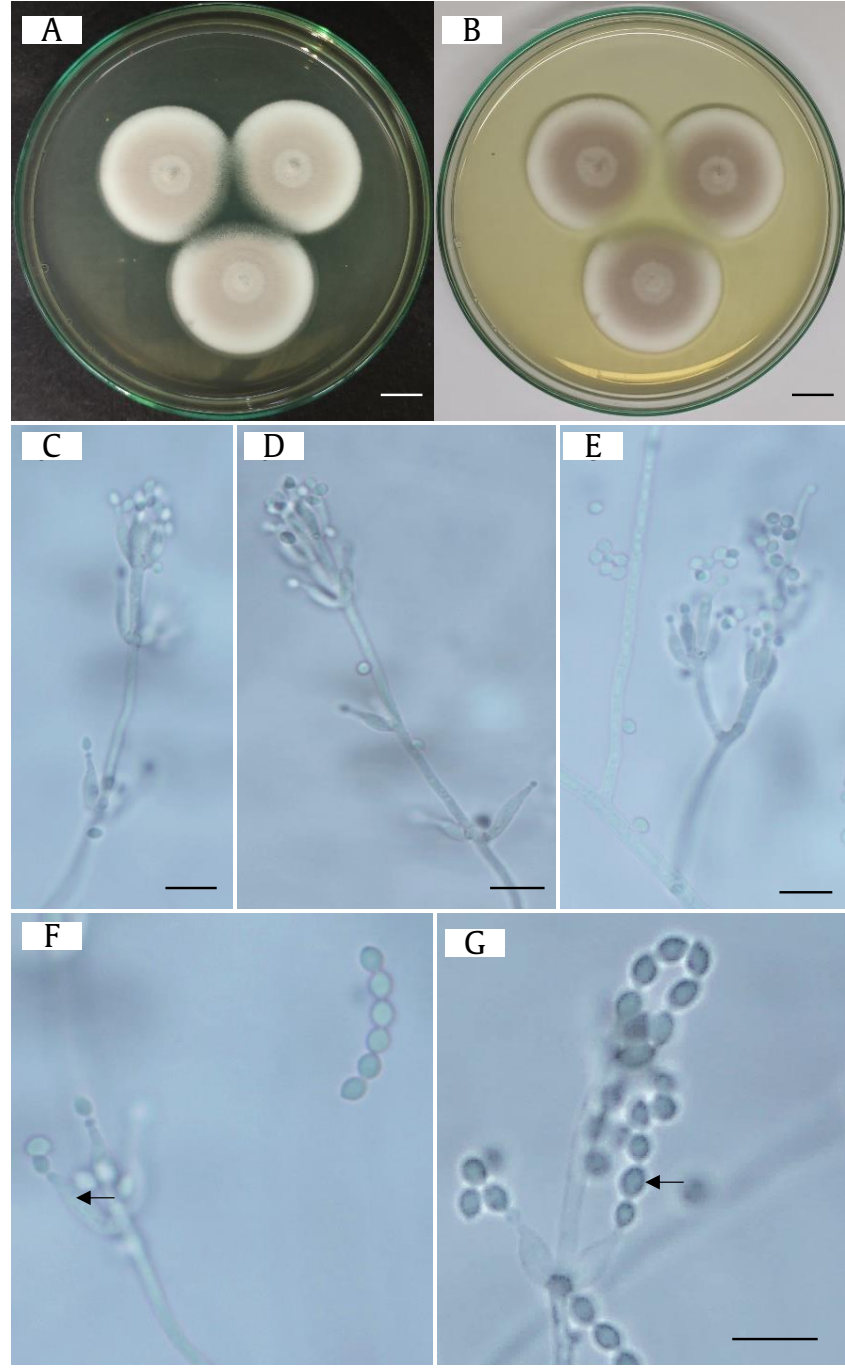

Figure 1. Colony and microscopic structures of Purpureocillium lilacinum IPBCC.19.1498 grown on PDA at 7 days after inoculation. (A-B) IPBCC.19.1498 sporulating colonies on dark and light backgrounds at $27^{\circ} \mathrm{C}$, (C-D) conidiophore, (E) branched conidiophore, (F) phialides, $(G)$ typical fusiform conidia. Scale bars are $1 \mathrm{~cm}(\mathrm{~A}-\mathrm{B})$ and $10 \mu \mathrm{m}(\mathrm{C}-\mathrm{G})$.

likelihood value -1689.9489 shown in Figure 2. A discrete gamma distribution was used to model evolutionary rate differences among sites ( 5 categories $(+G$, parameter $=0.2150)$ ). The tree is drawn to scale, with branch lengths measured in the number of substitutions per site. Bootstrap values above $50 \%$ are indicated above branches. A bootstrap value greater than $70 \%$ is considered strong. The phylogenetic tree constructed showed that P. lilacinum IPBCC.19.1498 is in the same cluster with P. lilacinum AB_103380 with bootstrap value $99 \%$ and sisters to P. lavendulum CBS 128677 with $99 \%$ bootstrap value. 
Table 1. ITS rDNA of organisms used in phylogenetic tree construction

\begin{tabular}{llc}
\hline Taxa & Strain/isolate & ITS GenBank accession number \\
\hline Purpureocillium lilacinum & IPBCC.19.1498 & \\
P. lilacinum & & AB103380 \\
P. lavendulum & CBS 128677 & MH864976 \\
Tolypocladium album & CBS 869.73 & NR_155018 \\
T. cylindrosporum & ARSEF 2920 & MG228381 \\
T. ovalisporum & CBS 700.92 & NR_155019 \\
Drechmeria balanoides & CBS 250.82 & NR_155044 \\
D. campanulata & IMI 356051 & NR_155045 \\
D. zeospora & CBS 335.80 & NR_155046 \\
Verticillium zeosporum & CBS 335.80 & AJ292419 \\
V. campanulatum & IMI 356051 & AJ292416 \\
Hypomyces samuelsii & CBS 127157 & MH864448 \\
H. semicircularis & CBS 705.88 & NR_121425 \\
Cladobotryum semicirculare & CBS 705.88 & FN859417 \\
C. tchimbelense & CBS 127166 & MH864455 \\
Haptocillium glocklingiae & CBS 101434 & NR_137654 \\
Paracremonium binnewijzendii (outgroup) & CBS 143277 & NR_157491 \\
\hline
\end{tabular}

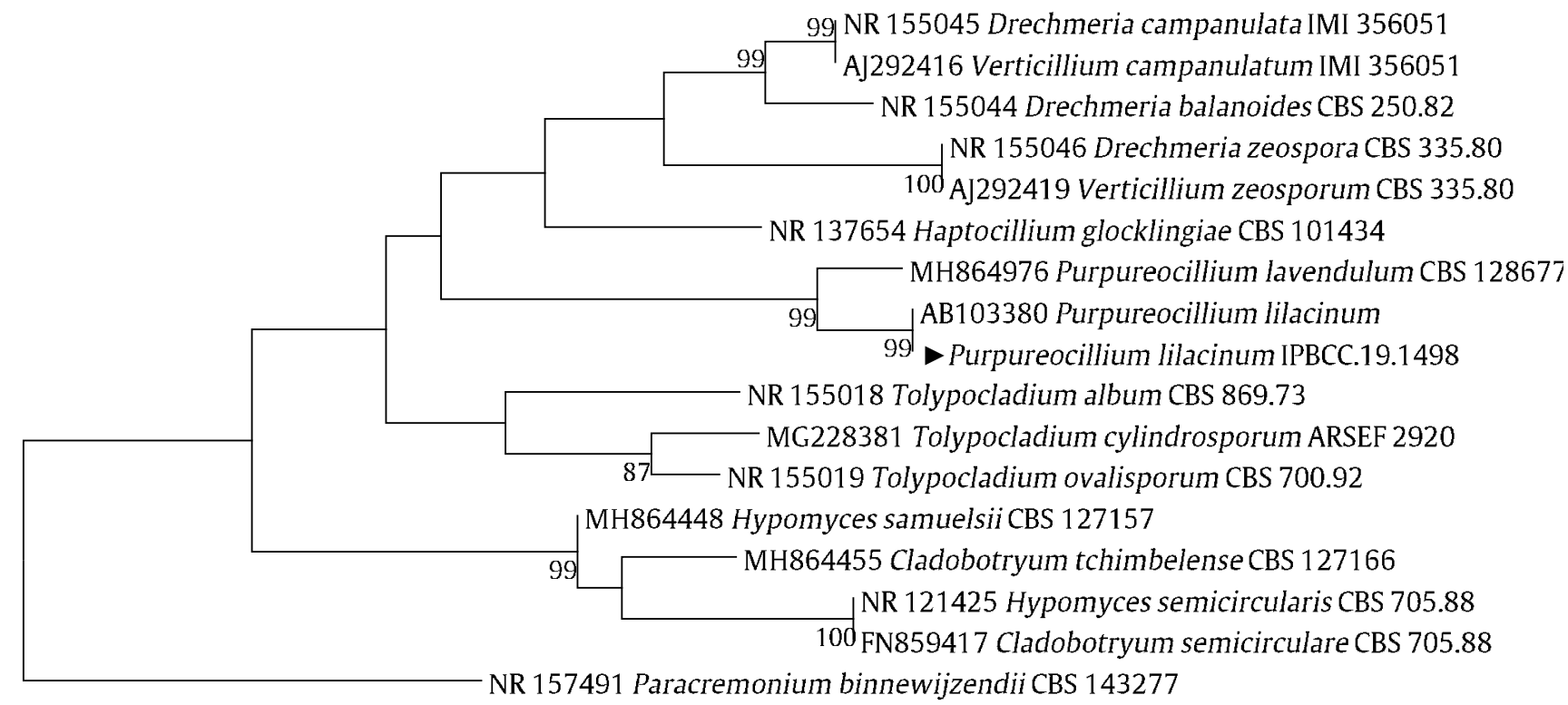

0.01

Figure 2. Phylogenetic tree of ITS rRNA gene obtained by maximum likelihood analysis. Phylogenetic analysis was performed on the basis of 665 unambiguously aligned positions of ITS rRNA gene with Paracremonium binnewijzendii as outgroup. Bootstrap values are indicated at the nodes

\subsection{In Vitro Inhibitory Pancreatic Lipase and Assay of Purpureocillium lilacinum IPBCC.19.1498 Extract}

The inhibitory effect of P. lilacinum IPBCC.19.1498 crude extracts on pancreatic lipase activity is presented in Figure 3. Both P. lilacinum IPBCC.19.1498 ethyl acetate and butanol extracts inhibited the activity of pancreatic lipase in a dose dependent manner. The extracts show increased inhibition with increased extract concentration from 250 to $1,000 \mu \mathrm{g} \cdot \mathrm{mL}^{-1}$. The inhibitory activity observed for both extracts shows the inhibitory concentration 50
$\left(\mathrm{IC}_{50}\right)$ value was between 250 to $500 \mu \mathrm{g} \cdot \mathrm{mL}^{-1}$ of crude extract.

Both extracts were then chromatographed in silica and XAD resins and subjected to the gradual polarity of eluent to obtain 12 fractionated extracts separated based on eluent used. All fractionated extracts from ethyl acetate and butanol showed inhibitory activity above $50 \%$, with the highest activity found in fraction 5 of ethyl acetate extract and fraction 12 of butanol extract at $93.41 \%$ and $62.76 \%$ inhibition, respectively (Figure 4). 
100

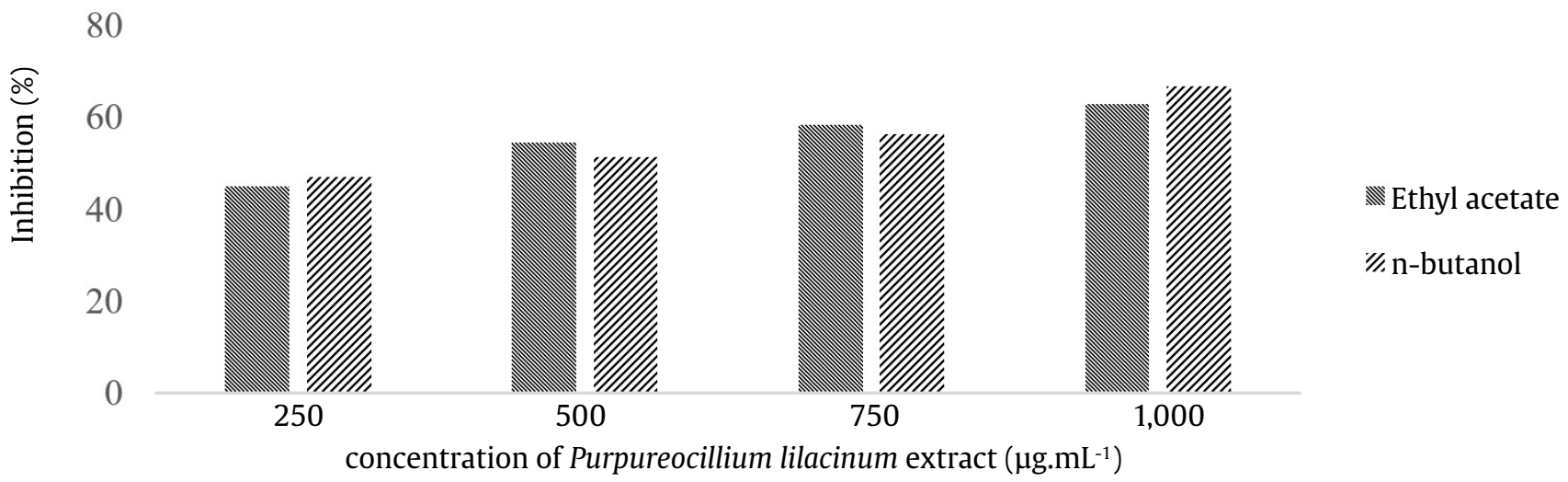

Figure 3. Effect of Purpureocillium lilacinum crude extracts on pancreatic lipase activity. Extract of ethyl acetate and butanol were measure thrice. Values are inhibition (\%) converted from means of pNP absorbance

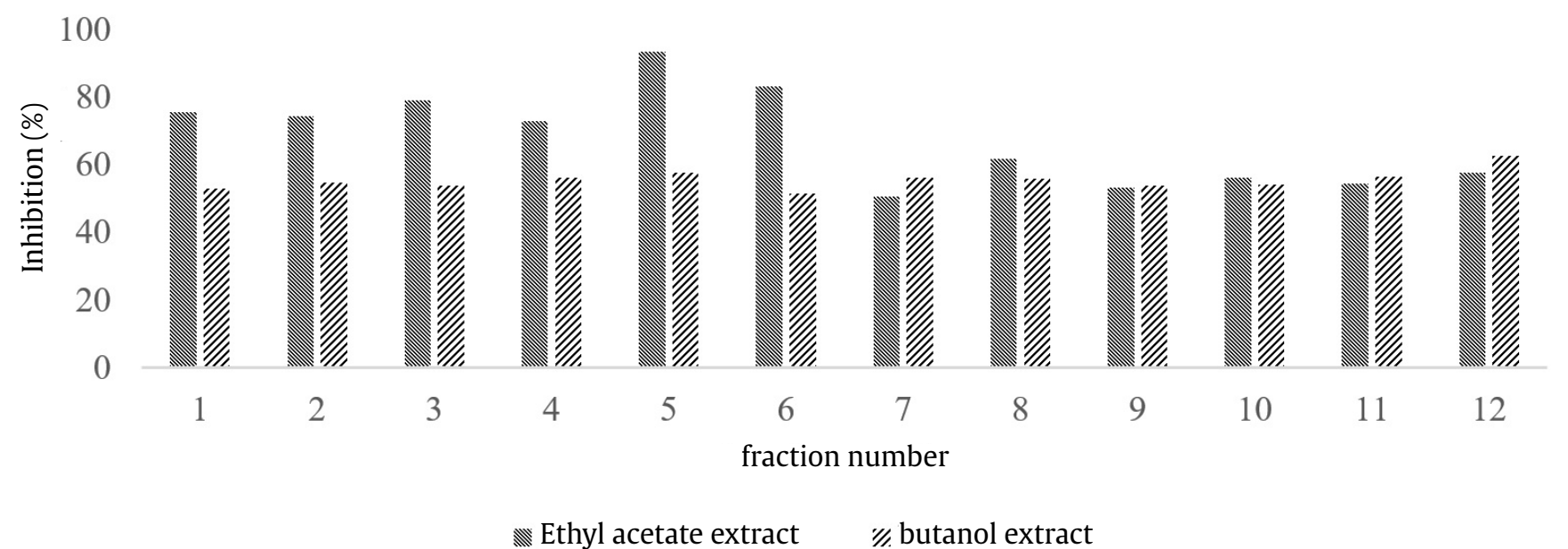

Figure 4. Effect of Purpureocillium lilacinum fractionated extracts of ethyl acetate and butanol on pancreatic lipase activity. All fractionated extracts were measured thrice. Values are inhibition (\%) converted from means of pNP absorbance

Fraction 5 of ethyl acetate extract was chosen as the most active fractionated extract for $\mathrm{IC}_{50}$ and enzyme kinetics analyses. The $\mathrm{IC}_{50}$ can be determined by constructing a dose-response curve and examining the effect of different concentrations of inhibitors on enzyme activity. The $\mathrm{IC}_{50}$ value is determined by the concentration needed to inhibit half of the maximum enzymatic response. $\mathrm{IC}_{50}$ values can also be used to compare the potency of inhibitors. In this study, the $\mathrm{IC}_{50}$ value was measured under different concentrations of the best-fractionated extract and orlistat as the positive control (data not shown). The most active fractionated extract had efficacy of $61.75 \%$ at $500 \mu \mathrm{g} \cdot \mathrm{mL}^{-1}$ and an $\mathrm{IC}_{50}$ of $220.60 \mu \mathrm{g} \cdot \mathrm{mL}^{-1}$; meanwhile, orlistat as positive control had IC ${ }_{50}$ of $30.57 \mu \mathrm{g} . \mathrm{mL}^{-1}$.

\subsection{Kinetic Behavior of Best-fractionated Extract}

The reaction rates of the most active fractionated extract are shown in Figure 5. The most active fractionated ethyl acetate extract of P. lilacinum had a competitive-type behavior on inhibition of pancreatic lipase based on the maximum rate $\left(\mathrm{V}_{\text {max }}\right)$ not significantly changing, and the enzyme constant $\left(\mathrm{K}_{\mathrm{M}}\right)$ increasing from $2.02 \mathrm{mM}$ to 5.47 $\mathrm{mM}$. The increased value of $\mathrm{K}_{\mathrm{M}}$ means the presence of substrate reduces the inhibitory activity of the extract. The kinetics parameters are presented in Table 2. 


\subsection{Fungal Metabolites Identification by LC- MS/MS QTOF Screening}

The metabolite screening of the most active fractionated $P$. lilacinum extract by LC-MS/MS QTOF showed 33 metabolites dominated by flavonoids, tannins, and terpenes. Three out of the identified metabolites are reported as lipase inhibitors, namely: galangin, kaemferol, and quercetin. The characteristics of the three predicted metabolites are presented in Table 3.
Table 2. Kinetic parameters of pancreatic lipase in the presence of the most active fractionated extract as inhibitor

\begin{tabular}{lccc}
\hline & $\mathrm{K}_{\mathrm{M}}(\mathrm{mM})$ & $\begin{array}{c}\mathrm{V}_{\max } \\
\left(\mathrm{mM}^{-m^{-1}}\right)\end{array}$ & $\begin{array}{c}\text { Type of } \\
\text { inhibition }\end{array}$ \\
\hline $\begin{array}{l}\text { Normal activity } \\
\text { (without inhibitor) }\end{array}$ & 2.02 & 388.80 & \\
$\begin{array}{l}\text { Most active } \\
\text { fractionated }\end{array}$ & 5.47 & 382.62 & competitive \\
$\begin{array}{l}\text { Purpureocillium } \\
\text { lilacinum extract }\end{array}$ & & & \\
as inhibitor & & & \\
\hline
\end{tabular}

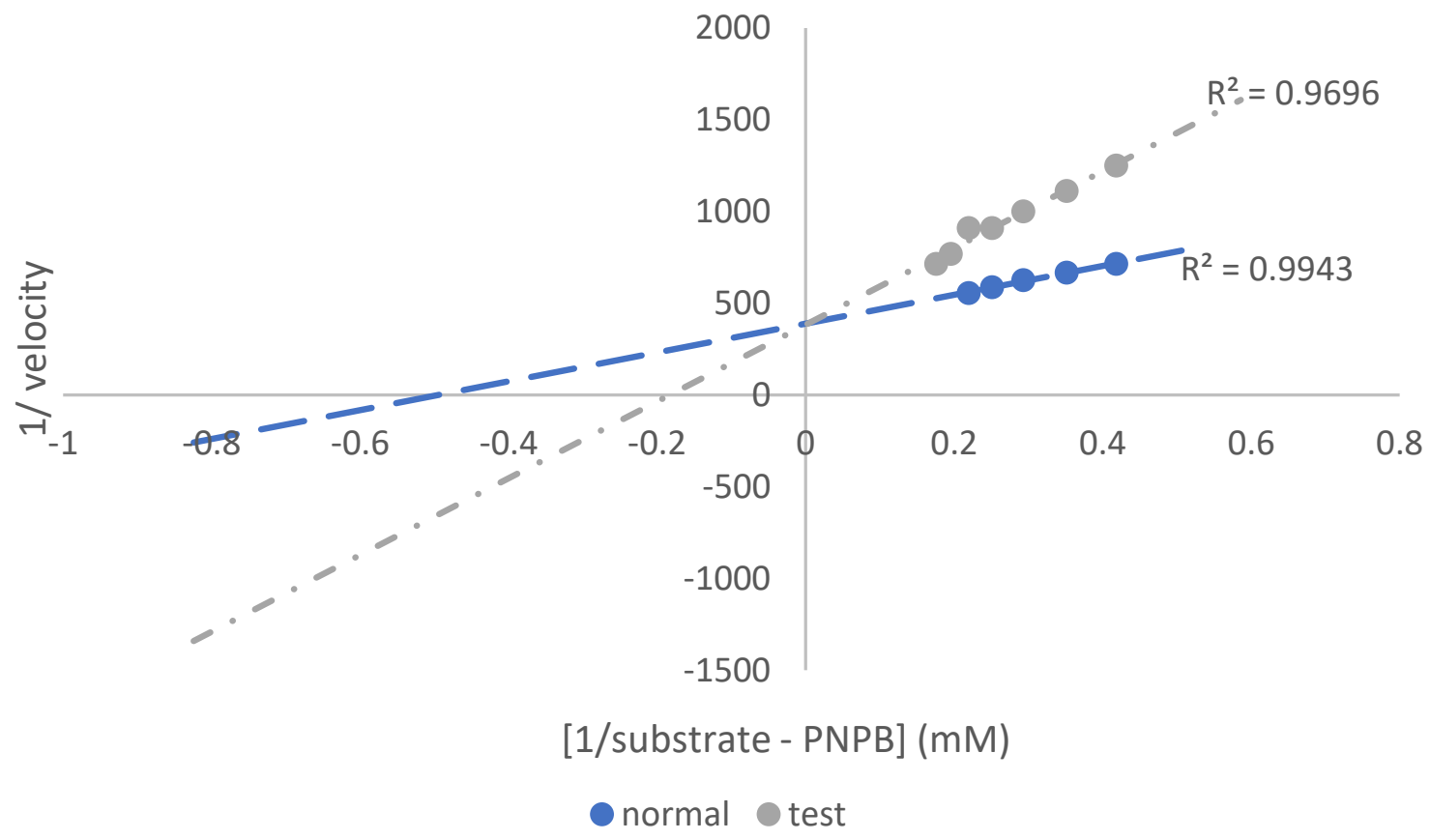

Figure 5. Substrate transformation in the presence and absence of the most active fractionated extract of Purpureocillium lilacinum. Determination of the kinetic parameters reaction rate of pancreatic lipase on pNPB according to Lineweaver-Burk Plot

Table 3. Predicted metabolites identified with LC-MS/MS QTOF from the most active fractionated extract of Purpureocillium lilacinum as pancreatic lipase inhibitor

\begin{tabular}{|c|c|c|c|c|c|c|}
\hline Compound name & IUPAC name & ESI mode & Observed RT (min) & Response & $\begin{array}{c}\text { Activity based on } \\
\text { reference }\end{array}$ & Reference \\
\hline $\begin{array}{l}\text { Galangin } \\
\text { (Norizalpinin) }\end{array}$ & $\begin{array}{l}\text { 3,5,7-trihydroxy-2- } \\
\text { phenylchromen- } \\
\text { 4-one }\end{array}$ & + & 6.55 & 17638 & $\begin{array}{l}\text { Not defined, } \mathrm{IC}_{50}: \\
48.20 \mathrm{mg}^{-} \mathrm{mL}^{-1}\end{array}$ & $\begin{array}{l}\text { Kumar and } \\
\text { Alagawadi } \\
2013\end{array}$ \\
\hline Kaempferol & $\begin{array}{l}\text { 3,5,7-trihydroxy- } \\
\text { 2-(4-hydroxy } \\
\text { phenyl)chromen- } \\
\text { 4-one }\end{array}$ & - & 12.60 & 2335 & $\begin{array}{c}\text { Competitive } \\
\text { inhibition }\end{array}$ & Li et al. 2020 \\
\hline Quercetin & $\begin{array}{l}\text { 2-(3,4-dihydroxy } \\
\text { phenyl)-3,5,7- } \\
\text { trihydroxy } \\
\text { chromen-4-one }\end{array}$ & - & 13.23 & 1008 & $\begin{array}{l}\text { Mixed type } \\
\text { inhibition }\end{array}$ & $\begin{array}{l}\text { Martinez- } \\
\text { Gonzalez } \\
\text { et al. } 2017\end{array}$ \\
\hline
\end{tabular}




\section{Discussion}

The fungus was identified as Purpureocillium lilacinum IPBCC.19.1498 based on morphological and molecular characteristics, including the phylogenetic tree. The fungus obtained in this study is in the same clade with soil fungus $P$. lilacinum (AB_103380) with a bootstrap value of $99 \%$. The genus Purpureocillium is proposed by Luangsa-Ard et al.(2011) for Paecilomyces lilacinus, along with Paecilomyces nostocoides, Isaria takamizusanensis, and Nomuraea atypicola, which belongs to Ophiocordycipitaceae based on the phylogenetic analysis of the 18S rRNA. The genus was proposed because the type species of Paecilomyces, $P$. variotii, is located in the family of the Trichocomaceae (Eurotiales) near Aspergillus, Penicillium and related species, forming a sister clade with the Onygenales (Luangsa-Ard et al. 2004; Sung et al. 2007; LuangsaArd et al. 2011).

Purpureocillium lilacinum is commonly reported as a terrestrial fungus, commonly occurring as a saprobic species isolated from soil, decaying vegetation, insects and insect larvae, nematodes, and other animals. Although widely reported as a component of the soil mycobiota, several strains were reported to cause keratitis typically occurring by external invasion (Domniz et al. 2001; Yuan et al. 2009). It has also been reported that $P$. lilacinum has been isolated from deep seawater samples in China and associated with a sponge from Malaysia (Cui et al. 2013; Mosadeghzad et al. 2013). But none have been reported from Indonesia.

Purpureocillium lilacinum is categorized as a facultative marine fungi since the fungus has the ability to grow on medium without sea water. Therefore, there is the possibilty the fungus was carried from land by streams and rivers into the sea and filtered by sponges. The capacity of $P$. lilacinum to colonize substrates under harsh conditions with low nutrient concentrations and low oxygen levels suggests that this species is able to survive in sea water (Mountfort and Rhodes 1991; Vigueras et al. 2008). Moreover, strains of Purpureocillium sp. have been reported to survive in a wide range of temperatures and $\mathrm{pH}$, which allows them to grow in a variety of substrates and makes them a rich source of biologically active natural products (Mosadeghzad et al. 2013). Purpureocillium lilacinum was frequently found in water distribution systems, including water tanks, sinks, showers (including drains), toilets, and air in a three-year study by Anaissie et al. (2003). The fungi can survive in water distribution systems and form a biofilm with other genera such as Aspergillus, Fusarium, and Acremonium (Anaissie et al. 2003).
Numerous kinds of marine fungi have been reported to produce diverse secondary metabolites with potential as medicine for many diseases. Purpureocillium lilacinum has produced diverse metabolites with unique properties such as $\alpha$-pyrone analogue phomaligol A, exhibiting antibacterial activity against Staphylococcus aureus, methicillin-resistant $S$. aureus and multidrugresistant S. aureus, leucinostatin A and B as antibacterial, antifungal, and antitumor agent, and caused uncoupling effect on rat liver mitochondrial function. Other metabolites such as phomapyrone $C$ also showed antibacteria activity against Acinetobacter baumannii, and 1,2-dilinolylglycero-O-4'-(N,N,N-trimethyl)homoserine, methyl myristate and cerebroside $\mathrm{B}-\mathrm{D}$ inhibited the human cancer K562, MCF-7, HL-60, and BGC-823 cell lines. Purpureocillium lilacinum also reported to produce a pyridone alkaloid, paecilomide as acetylcholine esterase inhibitor, and cerebrosides A showed nematicidal activity against Bursaphelenchus xylophilus (Arai et al. 1973; Fukushima et al. 1983; Elbandy et al. 2009; Yang et al. 2011; Cui et al. 2013; Teles and Takahashi 2013). The present study is the first report of $P$. lilacinum marine fungus associated sponge showing inhibitory effects on pancreatic lipase enzyme activity.

Pancreatic, endothelial, hepatic, lipoprotein lipases are human lipases that possesses structural similarity. Other tissues like lungs, kidneys, skeletal muscles, adipose tissue and placenta also secrete lipase enzymes. Pancreatic acinar cells secrete pancreatic lipase (triacylglycerol acyl hydrolase EC 3.1.1.3), an essential enzyme of pancreatic juice responsible for digestion, responsible for about $70 \%$ of triglyceride breakdown and absorption from dietary fat into the small intestine. Therefore, pancreatic lipase inhibitors are used for medication to treat obesity (Mukherjee 2003; Liu et al. 2020).

The $\mathrm{IC}_{50}$ value of pancreatic lipase inhibition with most active fractionated extract of $P$. lilacinum was $220.60 \mu \mathrm{g} . \mathrm{mL}^{-1}$ while orlistat was $30.57 \mu \mathrm{g} \cdot \mathrm{mL}^{-1}$. The potencies of several plant crude extracts reported to inhibit pancreatic lipase show $\mathrm{IC}_{50}$ values between 200 to $500 \mu \mathrm{g} \cdot \mathrm{mL}^{-1}$ such as Nelumbo nucifera and Salacia reticulata at $460 \mu \mathrm{g} \cdot \mathrm{mL}^{-1}$ and $264 \mu \mathrm{g} \cdot \mathrm{mL}^{-1}$, respectively (Birari and Bhutani 2007). Several plants extract used as slimming agents in jamu, namely Zingiber cassumunar, Guazuma ulmifolia, Tamarindus indica, Murraya paniculata, and Kaempferiae rotundae had been reported to have pancreatic lipase inhibitory activity. The activity of ethanol extract of Z. cassumunar, G. ulmifolia, and T. indica were $29.17 \%$ for $100 \mu \mathrm{g} \cdot \mathrm{mL}^{-1}, 25.13 \%$ for $60 \mu \mathrm{g} . \mathrm{mL}^{-1}$, and $49.0 \%$ for $150 \mu \mathrm{g} \cdot \mathrm{mL}^{-1}$, respectively. The activity of water extract of M. paniculata was $25.66 \%$ for $100 \mu \mathrm{g} \cdot \mathrm{mL}^{-1}$ and $K$. rotundae was $65.1 \%$ for $200 \mu \mathrm{g} \cdot \mathrm{mL}^{-1}$ (Iswantini et 
al. 2011, Pradono et al. 2011). Methanolic extract of several species used as medicinal plants in Korea also showed varied efficacy. Three of these plants were reported to have the highest efficacy, namely Eriochloa villosa (83\%), Orixa japonica (81.3\%), and Setaria italica (80.3\%) at $200 \mu \mathrm{g} \cdot \mathrm{mL}^{-1}$ extract concentrations (Sharma et al. 2005). Therefore, the extract of $P$. lilacinum in this study may potentially inhibit pancreatic lipase and could be categorized as a good source of inhibitor, similar to plant extracts mentioned above. Although the extract in this study had been fractionated once, the extract showed promising result.

The value of the $\mathrm{V}_{\max }$ was not significantly changed from $388.8 \mathrm{mM}$ pNP.min ${ }^{-1}$ to $382.62 \mathrm{mM}$ pNP.min ${ }^{-1}$, and the Michaelis-Menten constant $\left(\mathrm{K}_{\mathrm{M}}\right)$ increased from $2.02 \mathrm{mM}$ to $5.47 \mathrm{mM}$ in the presence of 500 $\mu \mathrm{g} \cdot \mathrm{mL}^{-1}$ fractionated extract. The $\mathrm{V}_{\max }$ value showed a saturated state where the enzymes were fully occupied with the substrate in the active site. In contrast, the Michaelis-Menten constant showed a stable enzymesubstrate complex where half of the $V_{\max }$ condition was achieved. The $\mathrm{K}_{\mathrm{M}}$ value also showed an affinity of the enzyme for substrate. A lower $\mathrm{K}_{\mathrm{M}}$ value shows a higher enzyme affinity to the substrate (Nelson and Cox 2017). Therefore, the competitive type inhibition exhibits an increasing value of $\mathrm{K}_{\mathrm{M}}$, which means that the substrate loses the affinity with the enzyme in the presence of the inhibitor. Thus, the most active fractionated extract of $P$. lilacinum is a competitivetype inhibitor.

A competitive inhibitor binds to the enzyme's active site and prevents the substrate from binding to that active site. A reversible competitive inhibitor diminishes the rate of catalysis by reducing the proportion of enzyme molecules bound to a substrate. At any given inhibitor concentration, competitive inhibition can be relieved by increasing the substrate concentration. With increased concentration, the substrate can outcompete the inhibitor for the active site (Berg et al. 2002). Meanwhile, with orlistat as an irreversible inhibitor, the enzyme-inhibitor complex is permanently unable to function as an enzyme and only production of new enzyme will allow reaction of the substrate. The irreversible inhibitor cannot be overcome by increasing the substrate concentration. The residence time of an irreversible inhibitor for pancreatic lipase in the intestinal lumen may lead to an unwanted effect in the body such as liquid stools, steatorrhea, fat-soluble vitamin deficiencies, fecal urgency, and flatus incontinence since there is a need to produce fresh enzyme to replace the inhibited lipase. The present study is the first step and exhibits the results of in vitro experiments, however it shows that $P$. lilacinum extract may become a potential source of metabolites to develop an anti-obesity drug with a competitive inhibitory mechanism.

Metabolite identification by LC-MS/MS QTOF revealed 33 metabolites dominated by flavonoids, tannins, and terpenes. Flavonoids and terpenes are two molecular groups known to inhibit pancreatic lipase (Birari and Bhutani 2007). The three identified metabolites, galangin, kaempferol, and quercetin, are known lipase inhibitors. Therefore, these three metabolites could be responsible for inhibiting pancreatic lipase in the most active fractionated extract assessed in this study.

In conclusion, the Indonesian marine fungus associated with Stylissa sp. sponges produced potential secondary metabolites with pancreatic lipase inhibition in in vitro tests and was isolated and identified as P. lilacinum IPBCC.19.1498. The fungal compounds were extracted from the culture broth using ethyl acetate and butanol, and the most active fractionated extract was obtained from ethyl acetate. The most active fractionated extract had an $\mathrm{IC}_{50}$ value of $220.60 \mu \mathrm{g} \cdot \mathrm{mL}^{-1}$. The $\mathrm{IC}_{50}$ value of the most active fraction obtained from the crude extract was eight times higher than the orlistat as positive control. The present study also revealed that the most active fractionated extract of $P$. lilacinum had a competitive inhibitory mechanism. Metabolite screening of the most active fractionated extract suggested the presence of three metabolites known to be responsible for pancreatic lipase inhibition, namely galangin, kaempferol, and quercetin.

\section{Conflict of Interest}

The authors declare no conflicts of interest. All experiments were undertaken in this study in compliance with the current laws of the country where they were performed.

\section{Acknowledgements}

This research was funded by the Ministry of Research, Technology and Higher Education, Indonesia through PMDSU (agreement No 4137/IT3. L1/PN/2018, 4282/IT3.L1/PN/2019 and 4144/IT3. L1/PN/20200), PKPI-PMDSU (agreement No T/38/ D3.2/KP.06.02/2019) and PPKI-SAME (agreement No T/2241/D3.2/KD.02.00/2019) Batch III. We thank to Scientific Diving Laboratories - IPB for sampling support and to BKSDA Jakarta for the sampling permit. 


\section{References}

Anaissie, E.J., Stratton, S.L., Dignani, M.C., Lee, C., Summerbell, R.C., Rex,J.H., Monson, T.P., Walsh, T.J., 2003. Pathogenic molds (including Aspergillus species) in hospital water distribution systems: a 3-year prospective study and clinical implications for patients with hematologic malignancies. Blood. 101, 2542-2546. https://doi. org/10.1182/blood-2002-02-0530

Arai, T., Mikami, Y., Fukushima, K., Utsumi, T., Yazawa, K., 1973. A new antibiotic, leucinostatin, derived from Penicillium lilacinum. Antibiot. 26, 157-161. https:// doi.org/10.7164/antibiotics.26.157

Berg, J.M., Tymoczko, J.L., Stryer, L., 2002. Enzymes Can Be Inhibited by Specific Molecules in Biochemistry, fifth ed. WH Freeman, New York.

Birari, R.B., Bhutani, K.K., 2007. Pancreatic lipase inhibitors from natural sources: unexplored potential. Drug. Discov. Today. 12, 879-889. https://doi.org/10.1016/j. drudis.2007.07.024

Carroll, A.R., Copp, B.R., Davis, R.A., Keyzers, R.A., Prinsep, M.R., 2019. Marine natural products. Nat. Prod. Rep. 36, 122-173. https://doi.org/10.1039/C8NP00092A

Chedda, U., Kaikini, A., Bagle, S., Seervi, M., Sathaye, S. 2016. In vitro pancreatic lipase inhibition potential of commonly used Indian spices. Journal of Pharmacy. $6,10-13$

Cui, X., Li, C.W., Wu, C.J., Hua, W., Cui, C.B., Zhu, T.J., Gu, Q.Q. 2013. Metabolites of Paecilomyces lilacinus ZBY-1 from deep-sea water and their antitumor activity. Int. Pharm. Res. 40, 177-186.

De Cesco, S., Kurian, J., Dufresne, C., Mittermaier, A.K. Moitessier, N., 2017. Covalent inhibitors design and discovery. Eur. J. Med. Chem. 138, 96-114. https://doi. org/10.1016/j.ejmech.2017.06.019

Debbab, A., Aly, A., Lin, W., Proksch, P., 2010. Bioactive compounds from marine bacteria and fungi. Microb. Biotechnol. 3, 544-563. https://doi.org/10.1111/j.17517915.2010.00179.x

Domniz. Y., Lawless. M., Sutton, G.L., Rogers, C.M., Meagher, L.J., 2001. Successful treatment of Paecilomyces lilacinus endophthalmitis after foreign body trauma to the cornea. Cornea. 20, 109-111. https://doi. org/10.1097/00003226-200101000-00021

Doshi, G., Aggarwal, G., Martis, E., Shanbhag, P., 2011. Novel antibiotics from marine sources. Int. J. Pharm. Sci. Nanotechnol. 4, 1446-1461. https://doi.org/10.37285/ ijpsn.2011.4.3.2

Ebada. S., Edrada, R., Lin, W., Proksch, P., 2008. Methods for isolation, purification and structural elucidation of bioactive secondary metabolites from marine invertebrates. Nat. Prot. 3, 1820-1831. https://doi. org/10.1038/nprot.2008.182

Elangbam, C.S., 2009. Current strategies in the development of anti-obesity drugs and their safety concerns. Vet. Pathol.46, 10-24. https://doi.org/10.1354/vp.46-1-10

Elbandy, M., Shinde, P.B., Hong, J., Bae, K.S., Kim, M.A., Lee, S.M., Jung, J.H., 2009. $\alpha$-Pyrones and yellow pigments from the sponge-derived fungus Paecilomyces lilacinus. Bull. Korean. Chem. Soc. 30, 188-192. https:// doi.org/10.5012/bkcs.2009.30.1.188

Fukushima, K., Arai, T., Mori, Y.J., Tsuboi, M., Suzuki, M., 1983. Studies on peptide antibiotics, leucinostatins. I: separation, physico-chemical properties and biological activities of leucinostatins $A$ and $B$. Antibiot. 36, 1606-1612. https://doi.org/10.7164/ antibiotics.36.1606

Hanif, N., Murni, A., Tanaka, C., Tanaka, J., 2019. Marine natural products from Indonesian waters. Mar. Drugs. 17, 364. https://doi.org/10.3390/md17060364
Heck, A.M., Yanovski, J.A., Calis, K.A., 2000. Orlistat a new lipase inhibitor for the management of obesity. Pharmacotherapy. 20, 270-279. https://doi. org/10.1592/phco.20.4.270.34882

Iswantini, D., Silitonga, R.F., Martatilofa, E., Darusman, L.K. 2011. Zingiber cassumunar, Guazuma ulmifolia, and Murraya paniculata extracts as antiobesity: in vitro inhibitory effect on pancreatic lipase activity. Hayati J. Biosci. 18, 6-10. https://doi.org/10.4308/hjb.18.1.6

Jiao, W.H., Xu, Q.H., Ge, G.B., Shang, R.Y., Zhu, H.R., Liu, H.Y., Cui, J., Sun, F., Lin, H.W., 2020. Flavipesides A-C, PKS-NRPS hybrids as pancreatic lipase inhibitors from a marine sponge symbiotic fungus Aspergillus flavipes 164013. Org. Lett. 22, 1825-1829. https://doi. org/10.1021/acs.orglett.0c00150

Kaila, B., Raman, M., 2008. Obesity: a review of pathogenesis and management strategies. Can.J. Gastroenterol. 22, 61-68. https://doi.org/10.1155/2008/609039

Katoch, M., Paul, A., Singh, G., Sridhar, S., 2017. Fungal endophytes associated with Viola odorata Linn. as bioresource for pancreatic lipase inhibitors. BMC. Complement. Altern. Med. 17, 385. https://doi. org/10.1186/s12906-017-1893-y

Kjer, J., Debbab, A., Aly, A.H., Proksch, P., 2010. Methods for isolation of marine-derived endophytic fungi and their bioactive secondary products. nat. prot. 5, 479490. https://doi.org/10.1038/nprot.2009.233

Kumar, S., Alagawadi, K.R., 2013. Anti-obesity effects of galangin, a pancreatic lipase inhibitor in cafeteria diet fed female rats. Pharm. Biol. 51, 607-613. https://doi. org/10.3109/13880209.2012.757327

Lam, D.D., Przydzial, M.J., Ridley, S.H., Yeo, G.S., Rochford, J.J., O'Rahilly, S., Heisler, L.K., 2008. Serotonin 5-HT2C receptor agonist promotes hypophagia via downstream activation of melanocortin 4 receptors. Endocrinology. 149, 1323-1328. https:// doi.org/10.1210/en.2007-1321

Li, S., Pan, J., Hu, X., Zhang, Y., Gong, D., Zhang, D., 2020. Kaempferol inhibits the activity of pancreatic lipase and its synergistic effect with orlistat.J. Function. Food. 72, 104041. https://doi.org/10.1016/j.jff.2020.104041

Liu, T.T., Liu, X.T., Chen, Q.X., Shi, Y., 2020. Lipase inhibitors for obesity: a review. Biomed. Pharma.cother. 128, 110314. https://doi.org/10.1016/j.biopha.2020.110314

Luangsa-Ard, J., Houbraken, J., van Doorn, T., Hong, S.B., Borman, A.M., Hywel-Jones, N.L., Samson, R.A., 2011. Purpureocillium, a new genus for the medically important Paecilomyces lilacinus. FEMS. Microbiol. Lett. 321, 141-149. https://doi.org/10.1111/j.15746968.2011.02322.x

Luangsa-Ard, J.J., Hywel-Jones, N.L., Samson, R.A., 2004. The polyphyletic nature of Paecilomyces Sensu lato based on 18S-generated rDNA phylogeny. Mycologia. 96, 773-780. https://doi.org/10.1080/15572536.2005 .11832925

Martinez-Gonzalez, A.I., Alvarez-Parrilla, E., Díaz-Sánchez, Á.G., de la Rosa, L.A., Núñez-Gastélum, J.A, VazquezFlores, A.A., Gonzalez-Aguilar, G.A., 2017. In vitro inhibition of pancreatic lipase by polyphenols: a kinetic, fluorescence spectroscopy and molecular docking study. Food. Technol. Biotechnol. 55, 519-530.

Mosadeghzad, Z., Zakaria, Z., Ahmad, A., Gires, U., Wickneswari, R., Pittayakhajonwut, P., Farahani, G.H.N., 2013. Chemical components and bioactivity of the marine-derived fungus Paecilomyces sp. collected from Tinggi Island, Malaysia. Chem. Nat. Comp. 62113 , 9-31304904. https://doi.org/10.1007/s10600-0130693-y 
Mountfort, D.O., Rhodes, LL., 1991. Anaerobic growth and fermentation characteristics of Paecilomyces lilacinus isolated from mullet gut. Appl. Environ. Microb. 57, 1963-1968. https://doi.org/10.1128/aem.57.7.19631968.1991

Mukherjee, M., 2003. Human digestive and metabolic lipases-a brief review. Journal. of Molecular. Catalysis. B: Enzymatic. 22, 369-376. https://doi.org/10.1016/ S1381-1177(03)00052-3

Nelson, D.L., Cox, M.M., 2017. Lehninger Principles of Biochemistrym, seventh ed. WH Freeman, New York.

Pimentel, M.R., Molina. G., Dionísio, A.P., Roberto, M., Junior, M., Pastore, G.M., 2011. The use of endophytes to obtain bioactive compounds and their application in biotransformation process. Biotechnol. Res. Int. 2011, 1-11. https://doi.org/10.4061/2011/576286

Pradono, D.I., Darusman, L.K., Susanti, A., 2011. Inhibition of in vitro pancreatic lipase by water and ethanol extracts of the leaves of tamarind (Tamarindus indica) and rhizome of Kunci pepet (Kaempferia rotunda). J. Nat. Indonesia. 13, 146-154. https://doi.org/10.31258/ jnat.13.2.146-154

Rachmi, C.N., Agho, K.E., Li, M., Baur, L.A., 2016. Stunting, underweight and overweight in children aged 2.0-4.9 years in Indonesia: prevalence trends and associated risk factors. PLoS ONE. 11, e0154756. https://doi. org/10.1371/journal.pone.0154756

Rachmi, C.N., Li, M., Baur, L.A., 2017. Overweight and obesity in Indonesia: prevalence and risk factors-a literature review. Public. health. 147, 20-29. https:// doi.org/10.1016/j.puhe.2017.02.002

Sambrook, J., Fritsch, E.F., Maniatis, T., 1989. Molecular Cloning: a Laboratory Manual, second ed, Cold Spring Harbor Laboratory Press, New York.

Sari, K., Amaliah, N., 2014. Sociodemographic factors and obesity on adults in Indonesia, year 2007 and 2010 (data analysis of basic health survey 2007 and 2010). Ekol. Kesehatan. 13, 328-339.

Sharma, N., Sharma, V.K., Seo, S.Y., 2005. Screening of some medicinal plants for anti-lipase activity.J. Ethnopharm. 97, 453-456. https://doi.org/10.1016/j.jep.2004.11.009

Singh, J., Petter, R.C., Baillie, T.A., Whitty, A., 2011. The resurgence of covalent drugs. Nat. Rev. Drug. Discov. 10, 307-317. https://doi.org/10.1038/nrd3410

Sung, G.H., Hywel-Jones, N.L., Sung, J.M., Luangsa-ard, J.J., Shrestha, B., Spatafora, J.W., 2007. Phylogenetic classification of Cordyceps and the clavicipitaceous fungi. Stud. Mycol. 57, 5-59. https://doi.org/10.3114/ sim.2007.57.01
Tang, W.Z., Liu, J.T., Hu, Q., He, R.J., Guan, X.Q., Ge, G.B., Han, H., Yang, F., Lin, H.W., 2020. Pancreatic lipase Inhibitory cyclohexapeptides from the marine sponge-derived fungus Aspergillus sp. 151304. Nat. Prod. Rep. 83, 22872293. https://doi.org/10.1021/acs.jnatprod.0c00549

Taylor, M.W., Radax, R., Steger, D., Wagner, M., 2007. Sponge associated mircroorganisms: evolution, ecology, and biotechnological potential. Microbiology. and Molecular. Biology. Reviews. 71, 295-347. https://doi. org/10.1128/MMBR.00040-06

Teles, A.P.C., Takahashi, J.A., 2013. Paecilomide, a new acetylcholinesterase inhibitor from Paecilomyces lilacinus. Microbiol. Res. 168, 204-210. https://doi. org/10.1016/j.micres.2012.11.007

Vigueras, G., Shirai, K., Martins, D., Franco, T.T., Fleuri, L.F., Revah, S., 2008. Toluene gas phase biofiltration by Paecilomyces lilacinus and isolation and identification of a hydrophobin protein produced thereof. Appl. Microbiol. Biot. 80, 147-154. https://doi.org/10.1007/ s00253-008-1490-6

Wahl, M., Goecke, F., Labes, A., Dobretsov, S., Weinberger, F., 2012. The second skin: ecological role of epibiotic biofilms on marine organisms. Front. Microbiol. 3, 292. https://doi.org/10.3389/fmicb.2012.00292

White, T.J., Bruns, T., Lee, S., Taylor, J., 1990. PCR Protocols: A Guide to Methods and Applications-A Laboratory Manual. Academic press, New York.

Yang, G.H., Sandjo, L., Yun, K., Leutou, A.S., Kim, G.D., Hong, D.C., Kang, J.S., Hong, J., Son, B.W., 2011. Flavusides A and $B$, antibacterial cerebrosides from the marinederived fungus Aspergillus flavus. Chem. Pharm. Bull. 59, 1174-1177. https://doi.org/10.1248/cpb.59.1174

Yang, M., Liang, L.F., Wang, T., Wang, H.Y., Liu, H.L., Guo, Y.W., 2017. Further brominated polyacetylenes with pancreatic lipase inhibitory activity from Chinese marine sponge Xestospongia testudinaria. J. Asian. Nat. Prod. Res. 19,732-737. https://doi.org/10.1080/10286 020.2016.1274308

Yuan, X., Wilhelmus, K.R., Matoba, A.Y, Alexandrakis, G., Miller, D., Huang, A.J., 2009. Pathogenesis and outcome of Paecilomyces keratitis. Am. J. Ophthalmol. 147, 691696. https://doi.org/10.1016/j.ajo.2008.11.016

Zhang, Y., Mu, J., Feng, Y., Kang, Y., Zhang, J., Cu, P.J., Wang, Y., Ma, L.F., Zhu, Y.H., 2009. Broad-spectrum antimicrobial epihitic and endophytic fungi from marine organism: isolation, Bioassay, and Taxonomy. Mar. Drugs. 7, 97122. https://doi.org/10.3390/md7020097 